\begin{tabular}{|c|c|c|}
\hline \multirow{3}{*}{$\begin{array}{r}\text { Case Reports in } \\
\text { Gastroenterology }\end{array}$} & \multirow{2}{*}{\multicolumn{2}{|c|}{ Case Rep Gastroenterol 2013;7:467-469 }} \\
\hline & & \\
\hline & $\begin{array}{l}\text { DOI: 10.1159/000355873 } \\
\text { Publisnea onine: Uctober 17, } 2013\end{array}$ & $\begin{array}{l}\text { ○ } 2013 \text { S. Karger AG, Basel } \\
\text { 1662-0631/13/0073-0467 } \$ 38.00 / 0 \\
\text { www.karger.com/crg }\end{array}$ \\
\hline & \multicolumn{2}{|c|}{$\begin{array}{l}\text { This is an Open Access article licensed under the terms of the Creative Commons } \\
\text { Attribution-NonCommercial } 3.0 \text { Unported license (CC BY-NC) (www.karger.com/OA } \\
\text { license), applicable to the online version of the article only. Distribution permitted for non } \\
\text { commercial purposes only. }\end{array}$} \\
\hline
\end{tabular}

\title{
Balloon against Jackhammer Disorder
}

\author{
A.L. Pelletier ${ }^{a} \quad$ D. Pospai ${ }^{a} \quad$ M. Merrouche ${ }^{b}$ \\ ${ }^{a}$ Service d'Hépato-Gastroentérologie, Hôpital Bichat-Claude Bernard, Paris, and \\ bervice d'Hépato-Gastroentérologie, Hôpital Louis Mourrier, Colombes, France
}

\section{Key Words}

Dysphagia · Esophageal disorder · Pneumatic dilatation · High-resolution manometry

\begin{abstract}
We describe a patient with dysphagia. The results of endoscopy, CT scan and echoendoscopy were normal. High-resolution manometry (HRM) showed esogastric junction dysfunction and hypercontractile peristaltic disorder. These HRM abnormalities completely disappeared after pneumatic esophageal dilatation. We discuss the treatment options and recovery of peristalsis after balloon dilatation.

(c) 2013 S. Karger AG, Basel
\end{abstract}

\section{Introduction}

High-resolution manometry (HRM) has profoundly changed the exploration of esophageal motility by allowing the measurement of many levels of the esophagus. The Chicago classification was developed to facilitate the interpretation of HRM and to promote widespread use of HRM in clinical practice even if some disorders have not yet been addressed [1,2]. Achalasia is characterized by impaired relaxation and the absence of normally propagated peristaltic contractions. We describe a patient with impaired esogastric junction relaxation and hypercontractile peristaltic disorder. Treatment led to an unusual recovery. 
Pelletier et al.: Balloon against Jackhammer Disorder

\section{Case Report}

A 37-year-old woman was referred to the hospital in November 2012 for dysphagia. The patient had been experiencing thoracic pain and dysphagia for solids for 6 months and lost $20 \mathrm{~kg}$. She had no prior medical history, was not taking any medication and did not smoke.

Esogastroduodenal endoscopy with biopsy was normal, excluding eosinophilic esophagitis. Echoendoscopy and thoracic CT scan were also normal, with no muscular thickening and no mediastinal tumor. Esogastroduodenal transit did not show any esophageal dilatation. HRM (Sierra Given) was performed. The catheter was placed transnasally and positioned to obtain recordings from the hypopharynx to the stomach with 36 circumferentially sensitive sensors. The catheter was attached to the nose. The transducers were calibrated. The HRM protocol included at least one $30 \mathrm{~s}$ assessment of basal sphincter pressure and ten $5 \mathrm{ml}$ water swallows in a supine position. Esogastric junction pressure was $32 \mathrm{~mm} \mathrm{Hg}$ (normal <43) and integrated relaxation pressure (IRP) $20 \mathrm{~mm} \mathrm{Hg}$ (normal <15), showing impaired relaxation after swallowing. The mean distal contractile integral (DCI) was $8,063 \mathrm{~mm} \mathrm{Hg} \mathrm{cm} \mathrm{s}$ and the contractile front velocity was $74.3 \mathrm{~cm} / \mathrm{s}$ (normal <6.3). Intrabolus pressure was high at $10 \mathrm{~mm} \mathrm{Hg}$ (normal <8.4), suggesting esophageal stasis.

Based on these results, pneumatic dilatation was performed with a Rigiflex balloon (Boston Scientific) positioned at the esogastric junction. The balloon was inflated to $30 \mathrm{~mm}$ 5 PSI for 1 min and 8 PSI for 1 min. Three months after endoscopy, the patient described clinical improvement with only two episodes of dysphagia, no chest pain, no regurgitation and weigh gain. HRM showed an esogastric junction pressure of $25 \mathrm{~mm} \mathrm{Hg}$ (normal <43), IRP $12 \mathrm{~mm} \mathrm{Hg}$ (normal <15), mean DCI 2,514 mm Hg cm s and normal peristalsis. The patient had no symptoms at 6 months.

\section{Discussion}

This case report shows a patient with abnormal basal esogastric junction pressure, high IRP and a hypercontractile peristaltic disorder of the esophagus. The association of these motility disorders is not described in the Chicago classification [2]. These results suggest a jackhammer esophagus due to the DCI above $8,000 \mathrm{~mm} \mathrm{Hg} \mathrm{cm} \mathrm{s}$, a result which is never found in control subjects. Achalasia is also suggested because of the IRP. Three clinically relevant subtypes of achalasia are described with panesophageal pressurization in type 2 but without the high DCI and no normal peristalsis. Jackhammer esophagus is rare $(4.1 \%$ in a tertiary center) and mainly revealed by dysphagia [3]. Roman et al. [3] described three patterns of hypercontractility: multipeaked and synchronized with breathing, multipeaked not synchronized with breathing and not multipeaked. The mean IRP was significantly higher in the group of patients without multipeaked contractions $(n=8)$.

The goal of treatment in this patient was to relieve dysphagia. Pneumatic dilatation was chosen because the HRM results were unusual. Laparoscopic myotomy was another option. A study comparing pneumatic dilatation and laparoscopic myotomy for achalasia after 2-year follow-up showed no difference between the two groups [4]. Pneumatic dilatation has been shown to be more effective in type 2 achalasia [5]. Peroral esophageal myotomy has also been described [6]. Injection of botulinum toxin is effective in relieving symptoms in $85 \%$ of patients, but symptoms recur in $50 \%$ at 6 months. This is an alternative treatment option which is mainly used for older or high-risk patients [7-9]. There is no definitive treatment and the existing options palliate dysphagia by lowering esogastric junction pres- 
Pelletier et al.: Balloon against Jackhammer Disorder

sure. There is no validated treatment for jackhammer disorder: pneumatic dilatation, myotomy and botulinum toxin injections should be considered for these patients.

The effect of treatment on the HRM results was also unusual. IRP and DCI were normal and peristalsis was present. One explanation is that the patient consulted soon after the first symptoms, while most patients wait years before undergoing HRM. Roman et al. [10] described partial recovery of peristalsis in some achalasia patients after myotomy. This suggests that esogastric junction obstruction may play a role in peristalsis failure in some achalasia patients.

In conclusion, we describe a patient with a rare esophageal motility disorder. The hypothesis of early-stage achalasia is possible and could provide information on the physiopathology of this disease. One session of dilatation had relieved the symptoms and the motility disorder at 6-month follow-up.

\section{References}

1 Wang YT, Yazaki E, Sifrim D: High-resolution manometry: esophageal disorders not addressed by the 'Chicago classification'. J Neurogastroenterol Motil 2012;18:365-372.

-2 Bredenoord AJ, Fox M, Kahrilas PJ, Pandolfino JE, Schwizer W, Smout AJ; International High Resolution Manometry Working Group: Chicago classification criteria of esophageal motility disorders defined in high resolution esophageal pressure topography. Neurogastroenterol Motil 2012;24(suppl 1):57-65.

-3 Roman S, Pandolfino JE, Chen J, Boris L, Luger D, Kahrilas PJ: Phenotypes and clinical context of hypercontractility in high-resolution esophageal pressure topography (EPT). Am J Gastroenterol 2012;107: $37-45$.

-4 Boeckxstaens GE, Annese V, des Varannes SB, Chaussade S, Costantini M, Cuttitta A, Elizalde JI, Fumagalli U, Gaudric M, Rohof WO, Smout AJ, Tack J, Zwinderman AH, Zaninotto G, Busch OR; European Achalasia Trial Investigators: Pneumatic dilation versus laparoscopic Heller's myotomy for idiopathic achalasia. N Engl J Med 2011;364:1807-1816.

5 Rohof WO, Salvador R, Annese V, Bruley des Varannes S, Chaussade S, Costantini M, Elizalde JI, Gaudric M, Smout AJ, Tack J, Busch OR, Zaninotto G, Boeckxstaens GE: Outcomes of treatment for achalasia depend on manometric subtype. Gastroenterology 2013;144:718-725; quiz e13-e14.

-6 Costamagna G, Marchese M, Familiari P, Tringali A, Inoue H, Perri V: Peroral endoscopic myotomy (POEM) for oesophageal achalasia: preliminary results in humans. Dig Liver Dis 2012;44:827-832.

7 Boeckxstaens G, Zaninotto G: Achalasia and esophago-gastric junction outflow obstruction: focus on the subtypes. Neurogastroenterol Motil 2012;24(suppl 1):27-31.

-8 Chuah SK, Hsu PI, Wu KL, Wu DC, Tai WC, Changchien CS: 2011 update on esophageal achalasia. World J Gastroenterol 2012;18:1573-1578.

-9 Vaezi MF: Achalasia: diagnosis and management. Semin Gastrointest Dis 1999;10:103-112.

10 Roman S, Kahrilas PJ, Mion F, Nealis TB, Soper NJ, Poncet G, Nicodème F, Hungness E, Pandolfino JE: Partial recovery of peristalsis after myotomy for achalasia: more the rule than the exception. JAMA Surg 2013;148:157-164. 